\title{
Anion-induced conformational changes in 2,7-disubstituted indole-based receptors
}

\author{
Damjan Makuc, ${ }^{a}$ Martina Lenarčič,${ }^{b}$ Gareth W. Bates, ${ }^{c}$ Philip A. Gale ${ }^{* c}$ and Janez Plavec ${ }^{* a, b}$ \\ Received (in $X X X, X X X)$ Xth $X X X X X X X X X 200 X$, Accepted Xth $X X X X X X X X X 200 X$ \\ ${ }_{5}$ First published on the web Xth $X X X X X X X X X 200 X$ \\ DOI: $10.1039 / b 000000 x$
}

The conformational preorganization and anion-induced conformational changes of indole-based receptors functionalized with amido group at $\mathrm{C} 2$ and a variety of amido, urea and thiourea moieties at $\mathrm{C} 7$ have been studied by the means of NMR spectroscopy. NOE experiments showed that anti10 anti orientation across $\mathrm{C} 2-\mathrm{C} 2 \alpha$ and $\mathrm{C} 7-\mathrm{N} 7 \alpha$ bonds is preferred for receptors 1-4 in acetone solution in the absence of anions. Anion-receptor interactions have been evaluated through ${ }^{1} \mathrm{H}$ and ${ }^{15} \mathrm{~N}$ chemical shift changes. In bis-amido 2,7-functionalised indoles the interaction with chloride and bromide anions primarily occurs at $\mathrm{H} 1$ proton. The formal introduction of urea and thiourea moieties increases the number of hydrogen bond donor sites which manifests itself in distribution

15 of halide-receptor interactions among $\mathrm{H} 1, \mathrm{H} 7 \alpha$ and $\mathrm{H} 7 \gamma$ protons. Acetate anions also interact strongly with indole and urea $\mathrm{NH}$ donor groups, whereas nitrate anions interact solely with $\mathrm{H} 7 \alpha$ and $\mathrm{H} 7 \gamma$ urea/thiourea protons. NOE enhancements in the presence of anions revealed that anionreceptor complexes favor syn-syn conformation of $\mathrm{C} 2$ and $\mathrm{C} 7$ substituents.

\section{Introduction}

20 The development of unique anion receptors, sensors and transporters is an area of intense research activity. ${ }^{1-5}$ Potential applications in the separation and extraction of anionic species, in the development of new sensing systems and in the design of new compounds that may have potential biological 25 activity has driven the synthesis of a plethora of receptors containing amides and thioamides, pyrroles and indoles, ureas and thioureas, ammonium, guanidinium and imidazolium moieties. ${ }^{6,7}$

Indole is employed by Nature in sulfate binding protein ${ }^{8}$ 30 and in the enzymatic active site of haloalkane dehalogenase ${ }^{9}$ to bind anions, however research in area of indole-based anion receptors ${ }^{10-20}$ is still at an early stage compared to the range of anion receptors based on pyrrole. ${ }^{21}$ The recognition and sensing properties of indole can be effectively regulated by 35 appending additional hydrogen bond donors to the indole skeleton. Amides have been widely used as hydrogen bond donor groups to bind anionic species ${ }^{22}$, whilst urea and thiourea moieties have been as well extensively employed as receptors for $\mathrm{Y}$-shaped oxo-anions through two directional 40 hydrogen bonds. ${ }^{23,24}$

In this study we have analysed the potential conformational preorganization and conformational changes of four previously synthesized bis-amido and mono-amido-mono-urea 2,7-functionalised indoles ${ }^{25}$ in the presence of a diverse range 45 of anionic guests with anions using NMR techniques. The indoles have a variety of substituents in the 7-position including secondary amides, urea and thiourea groups (Figure 1) and a carboxamidophenyl substituent in the 2-position. Crystal structure elucidation of solid-state complexes of these 50 species with anions and solution stability constant determinations in DMSO- $d_{6} / 0.5 \%$ water have been conducted previously. ${ }^{25}$

\section{Results}

NMR asssignment

${ }_{55}$ NMR spectroscopy has been used to evaluate and correlate structural and conformational properties of anion receptors 14 in acetone- $d_{6}$ to their preorganization for interaction with anions. As a first step, ${ }^{1} \mathrm{H},{ }^{13} \mathrm{C}$ and ${ }^{15} \mathrm{~N}$ resonances of $\mathbf{1 - 4}$ have been assigned based on the analysis of $1 \mathrm{D}$ proton and carbon ${ }_{60}$ spectra as well as ${ }^{13} \mathrm{C}-{ }^{1} \mathrm{H}$ and ${ }^{15} \mathrm{~N}-{ }^{1} \mathrm{H}$ correlations in 2D HSQC and HMBC spectra. The selected ${ }^{1} \mathrm{H}$ and ${ }^{15} \mathrm{~N}$ NMR chemical shifts are reported in Table 1, with the full list including ${ }^{13} \mathrm{C}$ NMR data available in the Experimental.
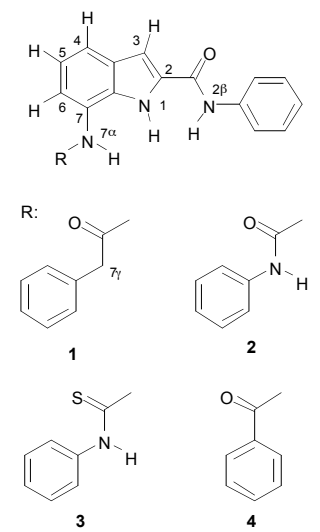

Figure 1. Anion receptors 1-4 and atom numbering. 
Table 1. Selected ${ }^{1} \mathrm{H}$ and ${ }^{15} \mathrm{~N}$ NMR Chemical Shifts for $\mathbf{1 - 4} .^{\mathrm{a}}$

\begin{tabular}{cccccccccc} 
& $\mathrm{H} 1$ & $\mathrm{H} 2 \beta$ & $\mathrm{H} 7 \alpha$ & $\mathrm{H} 7 \gamma$ & $\mathrm{H} 6$ & $\mathrm{~N} 1$ & $\mathrm{~N} 2 \beta$ & $\mathrm{N} 7 \alpha$ & $\mathrm{N} 7 \gamma$ \\
\hline $\mathbf{1}$ & 10.87 & 9.59 & 9.61 & 3.86 & 7.53 & 136.5 & 128.2 & 131.8 & - \\
$\mathbf{2}$ & 10.91 & 9.59 & 8.43 & 8.26 & 7.28 & 136.2 & 128.2 & 106.1 & 110.4 \\
$\mathbf{3}$ & 10.75 & 9.61 & 9.07 & 9.16 & 7.37 & 133.8 & 128.4 & 125.4 & 133.1 \\
$\mathbf{4}$ & 10.91 & 9.62 & 9.80 & - & 7.64 & 136.6 & 128.3 & 126.4 & - \\
\hline
\end{tabular}

${ }^{a}$ Reported chemical shifts (in ppm) correspond to NMR spectra acquired in acetone- $\mathrm{d}_{6}$ at $298 \mathrm{~K}$. The complete set of ${ }^{1} \mathrm{H}$ and ${ }^{13} \mathrm{C}$ NMR chemical shifts is available in the Experimental.

The different physicochemical properties of C7-substituents in 2,7-bisfunctionalized indoles $\mathbf{1 - 4}$ are reflected in NMR parameters and in particular in the chemical shielding of their inherent H-bond donors. Receptor 1 with its phenylacetylamido group exhibits $\mathrm{H} 7 \alpha$ and $\mathrm{N} 7 \alpha$ chemical 10 shifts of 9.61 and $131.8 \mathrm{ppm}$, respectively. The introduction of urea moiety in $\mathbf{2}$ manifests itself in the considerable upfield shifts of $\mathrm{H} 7 \alpha$ and $\mathrm{N} 7 \alpha$ to 8.43 and $106.1 \mathrm{ppm}$, respectively. Additional nitrogen atom N7 $\gamma$ in 2 exhibits chemical shift of $110.4 \mathrm{ppm}$ with the corresponding $\mathrm{H} 7 \gamma$ proton resonating at $158.26 \mathrm{ppm}$. Substitution of oxygen atom in $\mathbf{2}$ with sulfur in $\mathbf{3}$ causes considerable deshielding of $\mathrm{H} 7 \alpha, \mathrm{H} 7 \gamma, \mathrm{N} 7 \alpha$ and $\mathrm{N} 7 \gamma$ which is in agreement with the more acidic nature of thiourea moiety (Table 1). Moderate deshielding of $\mathrm{H} 7 \alpha$ in 4 with respect to $\mathbf{1}$ has been attributed to its benzoylamido group. On 20 the other hand, N7 $\alpha$ in $\mathbf{4}$ is shielded by $5.4 \mathrm{ppm}$ with regard to 1. Considerable changes of $\mathrm{H} 7 \alpha$ and $\mathrm{N} 7 \alpha$ chemical shifts in 14 correspond to variations in the electron donating/withdrawing nature of $N 7 \alpha$-substituents. The minute alterations of chemical shifts of $\mathrm{H} 2 \beta$ and $\mathrm{N} 2 \beta$ are in ${ }_{25}$ agreement with invariant $\mathrm{C} 2$ substituent. The ${ }^{13} \mathrm{C}$ chemical shifts changes are insignificant and do not reflect that different groups have been attached to $\mathrm{C} 7$ atom (Experimental).

${ }^{1} \mathrm{H}$ NMR chemical shift changes in 1-4 upon anion 30 interactions

The chemical shift values changed upon addition of one equivalent of chloride, bromide, nitrate and acetate ions added as tetrabutylammonium salts to receptors 1-4. The anionreceptor interactions induced a significant change in the ${ }_{35}$ chemical shielding of ${ }^{1} \mathrm{H}$ and ${ }^{15} \mathrm{~N}$ NMR resonances and only minor changes in ${ }^{13} \mathrm{C}$ resonances. Figure 2 illustrates ${ }^{1} \mathrm{H}$ chemical shift changes in $\mathbf{2}$ upon interaction with different anions. Significant deshielding of $\mathrm{H} 1, \mathrm{H} 7 \alpha$ and $\mathrm{H} 7 \gamma$ protons was observed upon addition of chloride or bromide anions to 40 solution of 2 (Figures 2a-c). Interaction of nitrate anions with 2 resulted in relatively smaller downfield shifts of the urea $\mathrm{H} 7 \alpha$ and $\mathrm{H} 7 \gamma$ protons (Figure $2 \mathrm{~d}$ ). The significant deshielding of all four $\mathrm{NH}$ protons of $\mathbf{2}$ indicated a strong interaction with acetate anions (Figure 2e).

45 A comparison of proton $\Delta \delta$ values induced upon addition of one equivalent of the four anions to receptors 1-4 is shown in Figure 3. The chemical shift of $\mathrm{H} 1$ shows the greatest change among all $\mathrm{NH}$ protons in $\mathbf{1}$ upon interaction with chloride (Figure 3a). Moderate chemical shift changes of $\mathrm{H} 2 \beta$ and $\mathrm{H} 7 \alpha$
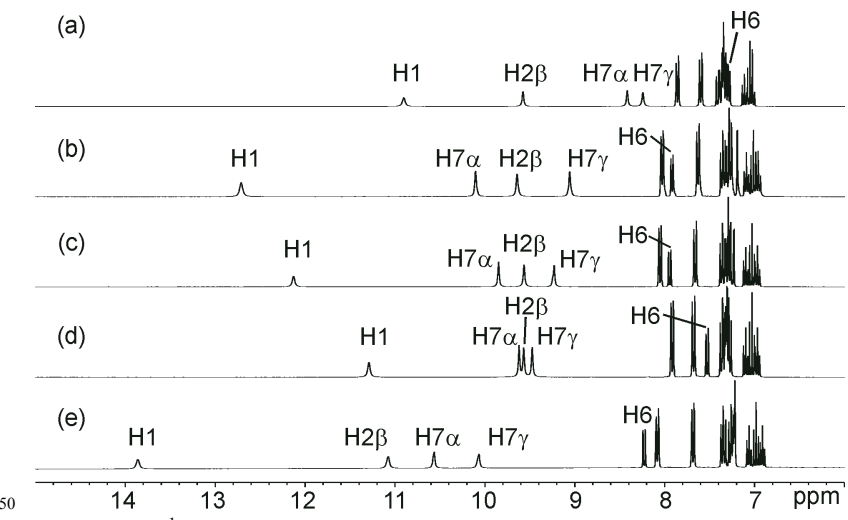

Figure 2. ${ }^{1} \mathrm{H}$ NMR spectra of $\mathbf{2}$ in the absence of anions (a) and upon addition of one equivalent of the following anions: chloride (b), bromide

(c), nitrate (d) and acetate (e). All spectra were recorded at $298 \mathrm{~K}$.

were observed for the $\mathbf{1} \cdot \mathrm{Cl}^{-}$complex, while the methylene ${ }_{55} \mathrm{H} 7 \gamma$

shows only a negligible change. The significantly larger $\Delta \delta$ values for both the urea $\mathrm{H} 7 \alpha$ and $\mathrm{H} 7 \gamma$ protons in $\mathbf{2} \cdot \mathrm{Cl}^{-}$should be noted $v s . \mathbf{1} \cdot \mathrm{Cl}^{-}$, whereas the $\mathrm{H} 2 \beta$ chemical shift change is smaller. However, the $\Delta \delta$ value for indole $\mathrm{H} 1$ is the largest ${ }^{1} \mathrm{H}$ ${ }_{60}$ chemical shift change upon formation of $\mathbf{2} \cdot \mathrm{Cl}^{-}$. A similar trend was observed for $3 \cdot \mathrm{Cl}^{-}$, where strong deshielding of $\mathrm{H} 7 \alpha$ and $\mathrm{H} 7 \gamma$ protons is in accordance with the higher acidity of thiourea group. Interestingly, a significant chemical shift change of $\mathrm{H} 6$ was observed in $\mathbf{3} \cdot \mathrm{Cl}^{-}$which is most probably ${ }_{65}$ the result of conformational changes and will be discussed later. In contrast to the other three receptors, the smallest $\Delta \delta$ value for $\mathrm{H} 7 \alpha$ and greatly increased deshielding of $\mathrm{H} 1$ and $\mathrm{H} 2 \beta$ protons upon formation of $4 \cdot \mathrm{Cl}^{-}$complex can be attributed to the benzoylamido substituent at $\mathrm{C} 7$ (Figure 3a).

70 The addition of bromide anions resulted in a slightly smaller downfield chemical shift changes in all four receptors in comparison to chloride anions ( $c f$. Figures 3a and $3 \mathrm{~b}$ ). As both anions are spherical, the main reason for these differences can be attributed to their different size and 75 basicity. $\mathrm{H} 1$ showed significant downfield shifts in $\mathbf{1} \cdot \mathrm{Br}^{-}$and $\mathbf{4} \cdot \mathrm{Br}^{-}$complexes, whereas $\mathbf{2} \cdot \mathrm{Br}^{-}$and $\mathbf{3} \cdot \mathrm{Br}^{-}$exhibited considerable deshielding of $\mathrm{H} 1, \mathrm{H} 7 \alpha$ and $\mathrm{H} 7 \gamma$. The latter suggested that all mentioned protons participate in the interaction with bromide anions.

so Notably smaller chemical shifts changes were observed upon addition of nitrate to 1-4 compared to the other anions studied. Receptors $\mathbf{1}$ and $\mathbf{4}$ which lack urea or thiourea moieties show relatively small $\Delta \delta$ values below $0.4 \mathrm{ppm}$, which lead us to suggest only minor nitrate-receptor 85 interactions are occurring in this case (Figure $3 \mathrm{c}$ ). On the other hand, in 2 and 3 deshielding of both $\mathrm{H} 7 \alpha$ and $\mathrm{H} 7 \gamma$ protons by up to $1.3 \mathrm{ppm}$ was observed upon addition of nitrate anions.

Significant $\Delta \delta$ values of up to $3.3 \mathrm{ppm}$ of NH protons in all 90 four studied receptors occurred upon addition of acetate anions to 1-4 (Figure 3d) consistent with the formation of strong complexes. ${ }^{25}$ 

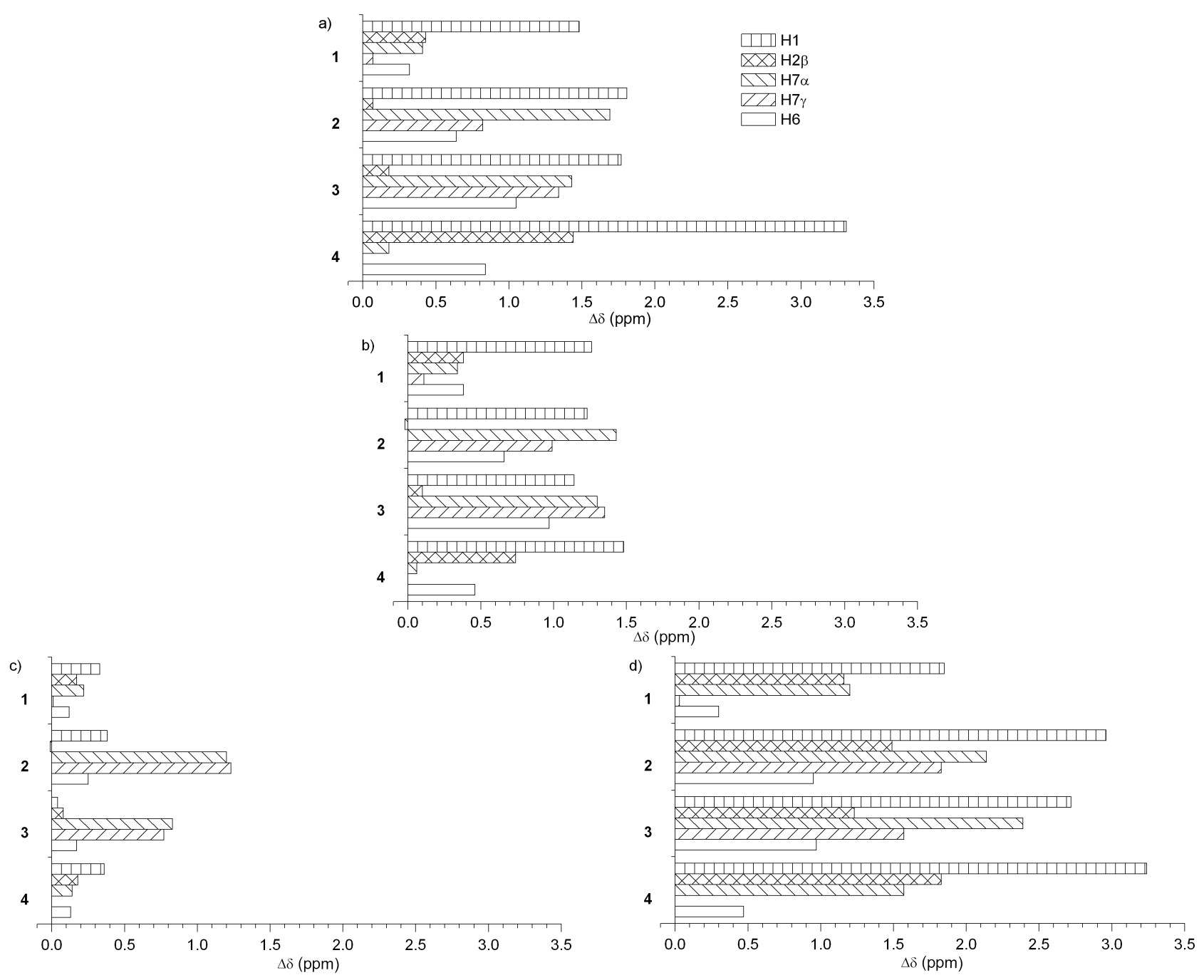

Figure 3. ${ }^{1} \mathrm{H}$ NMR chemical shift changes, $\Delta \delta=\delta$ (in the presence of anions) $-\delta$ (in the absence of anions), induced by addition of one equivalent of chloride (a), bromide (b), nitrate (c) and acetate (d) anions to receptors 1-4. Note, there is no H7 $\gamma$ proton in 4. 


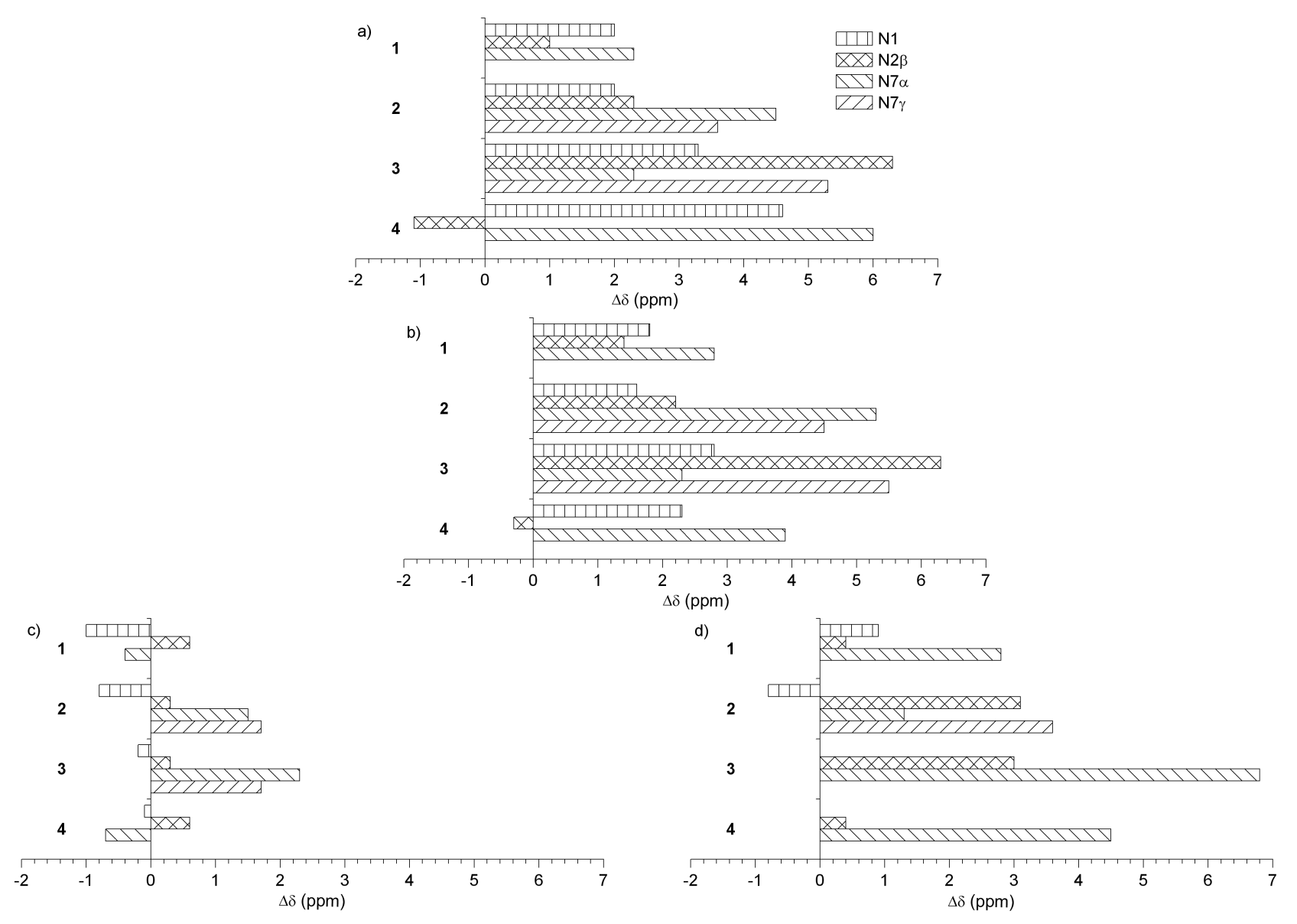

Figure 4. ${ }^{15} \mathrm{~N}$ NMR chemical shift changes, $\Delta \delta=\delta$ (in the presence of anions) $-\delta$ (in the absence of anions), induced by addition of one equivalent of chloride (a), bromide (b), nitrate (c) and acetate (d) anions to receptors 1-4. Note, ${ }^{15} \mathrm{~N}$ chemical shifts could not be determined for some atoms due to signal broadening after addition of acetate to 3 and $\mathbf{4}$. There is no N7 $\gamma$ in $\mathbf{1}$ and $\mathbf{4}$.

${ }^{15} \mathrm{~N}$ NMR chemical shift changes induced by anion interactions

Anion-receptor interactions evaluated through ${ }^{1} \mathrm{H}$ chemical ${ }_{10}$ shift changes have been supported by ${ }^{15} \mathrm{~N}$ NMR data (Figure 4). The largest $\Delta \delta$ values in $\mathbf{1}, \mathbf{2}$ and $\mathbf{4}$ upon addition of chloride and bromide anions were observed for $\mathrm{N} 7 \alpha$, whereas in 3 chemical shifts of $\mathrm{N} 2 \beta$ atom changed the most (Figures $4 \mathrm{a}$ and $4 \mathrm{~b}$ ). N2 $\beta$ and $\mathrm{N} 7 \gamma$ atoms in 2 and 3 were also

15 deshielded upon interaction with $\mathrm{Cl}^{-}$and $\mathrm{Br}^{-}$. Interestingly, N1 was deshielded upon addition of one equivalent of chloride and bromide anions, and shielded in the presence of nitrate anions in 1-4 (Figures $4 \mathrm{a}-\mathrm{c}$ ). The substitution of methylene $\mathrm{H} 7 \gamma$ in $\mathbf{1}$ with the $\mathrm{NH}$ group in $\mathbf{2}$ leads to increased 20 deshielding of N2 $\beta$ upon addition of chloride, bromide and acetate anions. The change was magnified even further with $\Delta \delta$ values up to $6.8 \mathrm{ppm}$ when urea (2) was swapped for thiourea moiety (3). A similar increase of N7 $\gamma$ deshielding $(\Delta \delta$ up to $5.5 \mathrm{ppm}$ ) in the presence of chloride and bromide was ${ }_{25}$ observed in 3 with respect to 2 . The interaction of $\mathrm{Cl}^{-}$with 4 leads to deshielding of $\mathrm{N} 1$ and $\mathrm{N} 7 \alpha$ by up to 4.6 and $6.0 \mathrm{ppm}$, respectively, whereas $\mathrm{N} 2 \beta$ is shielded in $\mathbf{4} \cdot \mathrm{Cl}^{-}$complex (Figure 4a). Analogous albeit smaller chemical shift changes were observed in $4 \cdot \mathrm{Br}^{-}$complex (Figure $4 \mathrm{~b}$ ). Addition of 30 nitrate anions results in lower $\Delta \delta$ values. The largest ${ }^{15} \mathrm{~N}$ chemical shift changes of up to $2.5 \mathrm{ppm}$ were observed for
N7 $\alpha$ and N7 $\gamma$ atoms in $\mathbf{2}$ and $\mathbf{3}$ (Figure 4c).

Conformational properties of receptors 1-4 in the absence and in the presence of anions

${ }_{35}$ Conformational equilibria of 2,7-functionalized indole receptors have been studied with the use of $1 \mathrm{D}$ difference NOE experiments. As an example, a 1D difference NOE spectra of $\mathbf{2}$ in the absence and upon addition of $\mathrm{Cl}^{-}$ions are shown in Figure 5. Four well resolved $\mathrm{NH}$ protons have 40 enabled unequivocal quantification of NOE enhancements. The predominant orientation of 2-phenylcarboxamide group in 2 has been established by the strong NOE enhancement of $14.5 \%$ at $\mathrm{H} 3$ upon saturation of the carboxamide $\mathrm{H} 2 \beta$ proton (Figure 5e). In full agreement, the saturation of $\mathrm{H} 2 \beta$ has ${ }_{45}$ resulted in a very weak NOE at $\mathrm{H} 1(0.5 \%)$. The orientation along $\mathrm{C} 7-\mathrm{C} 7 \alpha$ bond in $\mathbf{2}$ has been established through NOE enhancements among $\mathrm{H} 1, \mathrm{H} 6$ and $\mathrm{H} 7 \alpha$. Relatively strong $\{\mathrm{H} 7 \alpha\}$-H6 (7.3\%) and weaker $\{\mathrm{H} 1\}$-H7 $\alpha$ NOEs $(2.9 \%)$ have suggested the predominant conformation with $\mathrm{H} 7 \alpha$ pointing 50 away from indole $\mathrm{H} 1$ proton (Figures $5 \mathrm{c}$ and $5 \mathrm{~g}$ ). A considerable decrease of $\{\mathrm{H} 2 \beta\}-\mathrm{H} 3$ and $\{\mathrm{H} 7 \alpha\}-\mathrm{H} 6 \mathrm{NOE}$ enhancements to $7.5 \%$ and $2.7 \%$ was observed upon addition of chloride anions, respectively (Figures $5 \mathrm{f}$ and $5 \mathrm{~h}$ ). Furthermore, observation of NOE enhancements among H1${ }_{55} \mathrm{H} 2 \beta$ and $\mathrm{H} 1-\mathrm{H} 7 \alpha$ lead us to suggest conformational changes 
occur in 2 upon interaction with chloride anions ( $c f$. Figures $5 \mathrm{c}-\mathrm{d}, 5 \mathrm{e}-\mathrm{f}$ and $5 \mathrm{~g}-\mathrm{h})$.

The key NOE enhancements for $\mathbf{1 - 4}$ in the absence and in the presence of one equivalent of anions are presented in 5 Table 2. Relatively strong $\{\mathrm{H} 2 \beta\}-\mathrm{H} 3 \mathrm{NOE}(8.5 \%)$ in $\mathbf{1}$ is evidence to support the spatial proximity of $\mathrm{H} 2 \beta$ and $\mathrm{H} 3$ protons. Such orientation across $\mathrm{C} 2-\mathrm{C} 2 \alpha$ bond is in accordance with weak NOEs between $\mathrm{H} 2 \beta$ and $\mathrm{H} 1(\leq 1.0 \%)$. The saturation of $\mathrm{H} 7 \alpha$ has resulted in weak NOE enhancement 10 at $\mathrm{H} 1(\leq 1.0 \%)$, whereas stronger NOE was observed at $\mathrm{H} 6$ $(3.2 \%)$. The saturation of $\mathrm{H} 1$ yields a weak overall NOE at $\mathrm{H} 2 \beta$ and $\mathrm{H} 7 \alpha$ protons (Table 2). Although the $\mathrm{H} 2 \beta$ and $\mathrm{H} 7 \alpha$ signals overlap in $\mathbf{1}$, differences in overall NOE values in the absence and in the presence of anions have turned out to be 15 very informative in the assessment of conformational properties. Addition of one equivalent of chloride to $\mathbf{1}$ has altered several NOE enhancements. The saturation of $\mathrm{H} 2 \beta$ and $\mathrm{H} 7 \alpha$ has resulted in an increase of NOE at $\mathrm{H} 1$ from $\leq 1.0 \%$ to $6.9 \%$, and a decrease of $\{\mathrm{H} 2 \beta\}-\mathrm{H} 3 \mathrm{NOE}$ from $8.5 \%$ to $4.9 \%$ 20 and $\{\mathrm{H} 7 \alpha\}-\mathrm{H} 6 \mathrm{NOE}$ from $3.2 \%$ to $2.1 \%$ (Table 2). Furthermore, the saturation of $\mathrm{H} 1$ has caused major increase of overall NOE at $\mathrm{H} 2 \beta$ and $\mathrm{H} 7 \alpha(13.0 \%)$. Addition of bromide to $\mathbf{1}$ has triggered very similar changes which lead us to suggest an analogous predominant conformation as ${ }_{25}$ established for $\mathbf{1} \cdot \mathrm{Cl}^{-}$complex (Table 2 ). In contrast, addition

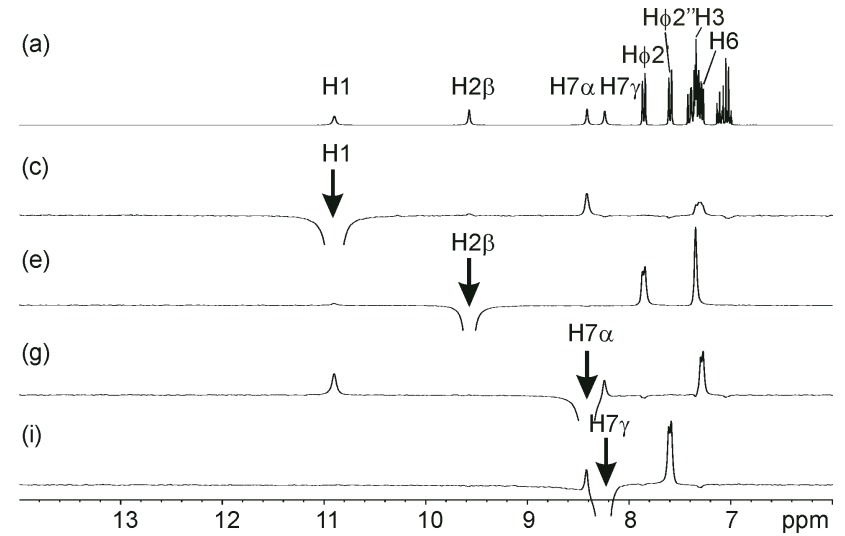

Table 2. The key NOE enhancements observed for 1-4 in the absence and in the presence of one equivalent of anions.

\begin{tabular}{|c|c|c|c|c|c|c|c|}
\hline \multirow{2}{*}{$\begin{array}{l}\text { Saturated: } \\
\text { Enhanced: }\end{array}$} & \multicolumn{2}{|c|}{$\mathrm{H} 2 \beta$} & \multicolumn{2}{|c|}{$\mathrm{H} 1$} & \multicolumn{2}{|c|}{$\mathrm{H} 7 \alpha$} & \multirow{2}{*}{$\begin{array}{l}\text { H6 } \\
\text { H7 } \alpha \\
\end{array}$} \\
\hline & $\mathrm{H} 3$ & $\mathrm{H} 1$ & $\mathrm{H} 2 \beta$ & $\mathrm{H} 7 \alpha$ & $\mathrm{H} 1$ & $\mathrm{H} 6$ & \\
\hline without & 8.5 & $\leq 1^{\mathrm{a}}$ & \multicolumn{2}{|c|}{$1.2^{\mathrm{a}}$} & $\leq 1^{\mathrm{a}}$ & 3.2 & 0.6 \\
\hline chloride & 4.9 & $6.9^{\mathrm{a}}$ & \multicolumn{2}{|c|}{$13.0^{\mathrm{a}}$} & $6.9^{\mathrm{a}}$ & 2.1 & 0.9 \\
\hline bromide & 4.1 & $6.7^{\mathrm{a}}$ & \multicolumn{2}{|c|}{$11.5^{\mathrm{a}}$} & $6.7^{\mathrm{a}}$ & 1.6 & 0.9 \\
\hline nitrate & 9.9 & $2.5^{\mathrm{a}}$ & \multicolumn{2}{|c|}{$5.2^{\mathrm{a}}$} & $3.6^{\mathrm{a}}$ & 4.4 & 1.9 \\
\hline acetate & 4.5 & $-{ }^{b}$ & \multicolumn{2}{|c|}{$-{ }^{b}$} & $-{ }^{b}$ & 2.5 & 0.1 \\
\hline without & 14.5 & 0.5 & 0.2 & 2.9 & 5.0 & 7.3 & 1.0 \\
\hline chloride & 7.5 & 12.0 & 13.6 & 12.9 & 13.8 & 2.7 & 0.9 \\
\hline bromide & 8.2 & 9.7 & 12.0 & 10.7 & 11.4 & 3.7 & 0.7 \\
\hline nitrate & 10.0 & 4.7 & 3.0 & 5.2 & 6.3 & 6.8 & 2.9 \\
\hline acetate & 1.5 & 12.9 & 15.8 & 10.2 & 8.8 & 0.9 & 0 \\
\hline without & 15.2 & 0 & 0.1 & 1.0 & $1.0^{\mathrm{c}}$ & $2.5^{\mathrm{c}}$ & $--^{d}$ \\
\hline chloride & 7.1 & 7.2 & 6.4 & 5.7 & $3.6^{\mathrm{c}}$ & $1.1^{\mathrm{c}}$ & 0.5 \\
\hline bromide & 6.9 & 5.8 & 5.3 & 4.4 & $3.8^{\mathrm{c}}$ & $1.4^{\mathrm{c}}$ & 0.2 \\
\hline nitrate & 15.3 & 1.4 & 1.1 & 0 & $0^{c}$ & $2.8^{\mathrm{c}}$ & 0.7 \\
\hline without & 15.3 & 0 & 0 & 0.9 & $1.5^{\mathrm{a}}$ & 6.5 & $0.6^{\mathrm{d}}$ \\
\hline chloride & 1.1 & 8.0 & 8.0 & 5.3 & 5.6 & $-{ }^{d}$ & $0.3^{\mathrm{d}}$ \\
\hline bromide & 7.3 & 8.2 & 6.8 & 5.4 & 5.9 & 3.9 & $0.5^{\mathrm{d}}$ \\
\hline nitrate & 13.1 & $2.5^{\mathrm{a}}$ & 1.3 & 2.3 & $3.9^{\mathrm{a}}$ & 5.9 & $1.0^{\mathrm{d}}$ \\
\hline
\end{tabular}

${ }^{\mathrm{a}} \mathrm{H} 2 \beta$ and $\mathrm{H} 7 \alpha$ were saturated simultaneously or integrated together due to small $\Delta \delta$ values. ${ }^{\mathrm{b}}$ Negative NOEs due to proton exchange. ${ }^{\mathrm{c}}$ Both $\mathrm{H} 7 \alpha$ 30 and $\mathrm{H} 7 \gamma$ were saturated simultaneously or integrated together due to small $\Delta \delta$ values. ${ }^{\mathrm{d}}{ }^{\mathrm{H}} \mathrm{H}$ signals were overlapped and pair-wise enhancements could not be quantified unequivocally.

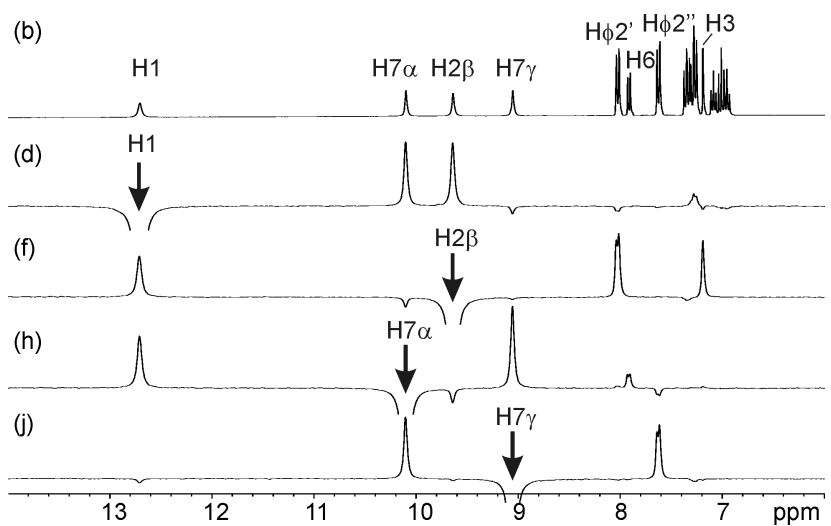

Figure 5. ${ }^{1} \mathrm{H}$ NMR spectra of 2 in the absence (a) and in the presence of $\mathrm{Cl}^{-}$ions (b), and corresponding 1D difference NOE spectra upon saturation of $\mathrm{H} 1$ (c-d), H2 $\beta$ (e-f), H7 $\alpha$ (g-h) and H7 $\gamma$ protons (i-j). All spectra were recorded at $298 \mathrm{~K}$.

of nitrate anions to 1 has resulted in strong $\{\mathrm{H} 2 \beta\}-\mathrm{H} 3 \mathrm{NOE}$ and moderate increase of $\{\mathrm{H} 7 \alpha\}-\mathrm{H} 6$ NOE which indicated negligible conformational changes in $\mathbf{1}$ upon interaction with $\mathrm{NO}_{3}^{-}$(Table 2). The decrease of $\{\mathrm{H} 2 \beta\}-\mathrm{H} 3$ and $\{\mathrm{H} 7 \alpha\}-\mathrm{H} 6$ ${ }_{40} \mathrm{NOEs}$ for $\mathbf{1} \cdot \mathrm{AcO}^{-}$complex is in agreement with conformational changes across $\mathrm{C} 2-\mathrm{C} 2 \alpha$ and $\mathrm{C} 7-\mathrm{N} 7 \alpha$ bonds. Unfortunately, negative values of other key NOEs due to proton exchange prevented more detailed conclusions regarding conformational changes of $\mathbf{1}$ upon interaction with 45 acetate anions.

The interaction of bromide anions with 2 resulted in increase of $\{\mathrm{H} 2 \beta\}-\mathrm{H} 1,\{\mathrm{H} 1\}-\mathrm{H} 2 \beta,\{\mathrm{H} 1\}-\mathrm{H} 7 \alpha$ and $\{\mathrm{H} 7 \alpha\}-\mathrm{H} 1$ NOEs (Table 2). Changes of NOE enhancements are analogous to those observed in $\mathbf{2} \cdot \mathrm{Cl}^{-}$, evidence for comparable 50 conformational changes in $\mathbf{2}$ upon interaction with bromide anions. Strong $\{\mathrm{H} 2 \beta\}-\mathrm{H} 3$ and $\{\mathrm{H} 7 \alpha\}-\mathrm{H} 6$ NOEs of $10.0 \%$ and $6.8 \%$, respectively, suggest only minor conformational
$\{\mathrm{H} 2 \beta\}-\mathrm{H} 3$ and $\{\mathrm{H} 7 \alpha\}-\mathrm{H} 6 \mathrm{NOE}$ values to $1.5 \%$ and $0.9 \%$, respectively (Table 2). Strong NOEs between $\mathrm{H} 1$ and $\mathrm{H} 2 \beta$, 55 and likewise between $\mathrm{H} 1$ and $\mathrm{H} 7 \alpha$ in $\mathbf{2} \cdot \mathrm{AcO}^{-}$complex indicate major conformational changes along $\mathrm{C} 2-\mathrm{C} 2 \alpha$ and $\mathrm{C} 7-\mathrm{N} 7 \alpha$ bonds.

Receptor 3 with its 7-thiourea moiety exhibited strong $\{\mathrm{H} 2 \beta\}-\mathrm{H} 3$ NOE (15.2\%) which indicated conformational 60 preorganization along $\mathrm{C} 2-\mathrm{C} 2 \alpha$ bond. The predominance of the conformer of 3 with $\mathrm{H} 2 \beta$ and $\mathrm{H} 3$ being spatially close is further supported by negligible NOEs between $\mathrm{H} 1$ and $\mathrm{H} 2 \beta$ protons $(<0.1 \%)$. The weak NOEs between $\mathrm{H} 1$ and $\mathrm{H} 7 \alpha$ $(1.0 \%)$ and a slightly stronger $\{\mathrm{H} 7 \alpha\}-\mathrm{H} 6 \mathrm{NOE}$ of $2.5 \%$ allude ${ }_{65}$ to the predominance of $\mathrm{C} 7-\mathrm{C} 7 \alpha$ conformer, where H6 and $\mathrm{H} 7 \alpha$ are spatially closer than $\mathrm{H} 1$ and $\mathrm{H} 7 \alpha$. The addition of chloride and bromide anions results in decrease of NOEs between $\mathrm{H} 2 \beta$ and $\mathrm{H} 3$ as well as between $\mathrm{H} 7 \alpha$ and $\mathrm{H} 6$ (Table 2). Moreover, the increase of $\mathrm{H} 1-\mathrm{H} 2 \beta$ and $\mathrm{H} 1-\mathrm{H} 7 \alpha$ NOEs is 
consistent with conformational changes in $\mathbf{3}$ upon addition of chloride and bromide anions. In the case of the $\mathbf{3} \cdot \mathrm{NO}_{3}{ }^{-}$ complex, small NOE changes were observed (Table 2). Regrettably, negative NOEs in $\mathbf{3} \cdot \mathrm{AcO}^{-}$complex NOEs 5 thwarted a conformational study of this complex.

The conformational preorganization of 4 , where $\mathrm{H} 2 \beta$ and $\mathrm{H} 7 \alpha$ point away from indole $\mathrm{H} 1$ proton, is supported by strong $\{\mathrm{H} 2 \beta\}-\mathrm{H} 3$ and $\{\mathrm{H} 7 \alpha\}-\mathrm{H} 6$ NOEs as well as weak NOE enhancements between $\mathrm{H} 1-\mathrm{H} 2 \beta$ and $\mathrm{H} 1-\mathrm{H} 7 \alpha$. The addition of 10 chloride or bromide anions triggers conformational changes in 4, which were clearly indicated by decreased $\{\mathrm{H} 2 \beta\}-\mathrm{H} 3$ and $\{\mathrm{H} 7 \alpha\}-\mathrm{H} 6$ NOEs and increased NOEs between indole $\mathrm{H} 1$ and both $\mathrm{H} 2 \beta$ and $\mathrm{H} 7 \alpha$ protons (Table 2). Insignificant changes of key NOEs in $\mathbf{4} \cdot \mathrm{NO}_{3}^{-}$complex lead us to suggest that 15 predominant conformation remained mostly unchanged upon addition of nitrate anions. The saturation of proton signals in 4. $\mathrm{AcO}^{-}$complex yielded negative NOEs, which did not allow detailed conformational analysis.

\section{Discussion}

20 Acquired heteronuclear NMR data on four different anion receptors showed distinct changes as a result of their interactions with anions. Both chemical shift changes and conformational rearrangements can be attributed to structural details of receptors 1-4 as well as the anions' properties 25 including their diverse binding affinities. Perusal of chemical shift changes showed correlation between the nature of $\mathrm{C} 7$ substituent and the magnitude and localization of chloridereceptor interactions. $\Delta \delta$ values in $\mathbf{1}$ suggested that interactions between $\mathrm{H} 1$ protons and chloride anions are the 30 strongest as deshielding is significantly more pronounced than for $\mathrm{H} 2 \beta$ or $\mathrm{H} 7 \alpha$ amide protons. Changing the phenylacetylamido moiety in $\mathbf{1}$ to a urea group in $\mathbf{2}$ led to increased deshielding of the $\mathrm{H} 7 \alpha$ and $\mathrm{H} 7 \gamma$ protons which suggested that the anion-receptor interactions in $\mathbf{2} \cdot \mathrm{Cl}^{-}$complex 35 involved the indole and urea $\mathrm{NH}$ protons. Our observed differences in proton $\Delta \delta$ values are in agreement with the published stability constants for $\mathbf{1} \cdot \mathrm{Cl}^{-}$and $\mathbf{2} \cdot \mathrm{Cl}^{-}$complexes. ${ }^{25}$ The comparison of structurally related indoles $\mathbf{2}$ and $\mathbf{3}$ showed similar chemical shifts changes for both receptors upon 40 addition of chloride anions. The largest deshielding of $\mathrm{H} 1$ and $\mathrm{H} 2 \beta$ protons was observed in $\mathbf{4} \cdot \mathrm{Cl}^{-}$with respect to corresponding complexes of $\mathbf{1 - 3}$, which suggested the predominant involvement of $\mathrm{H} 1$ and $\mathrm{H} 2 \beta$ donor groups in interaction with chloride anions.

45 Interaction of bromide anions with receptors 1-4 caused analogous albeit smaller chemical shift changes in comparison to chloride anions, in agreement with bromide's lower basicity. Considerable deshielding of the $\mathrm{H} 7 \alpha$ and $\mathrm{H} 7 \gamma$ protons was observed upon addition of $\mathrm{Y}$-shaped nitrate

${ }_{50}$ anions to $\mathbf{2}$ and $\mathbf{3}$ which contain urea and thiourea moieties, respectively. In contrast, only minor ${ }^{1} \mathrm{H}$ chemical shift changes were observed upon addition of $\mathrm{NO}_{3}{ }^{-}$anions to $\mathbf{1}$ and 4 which contain amide groups at $\mathrm{C} 2$ and $\mathrm{C} 7$. Urea and thiourea moieties were shown to be preferred for interaction 55 with trigonal planar anions due to their suitable shape and capability to form two hydrogen bonds. ${ }^{23}$ The largest ${ }^{1} \mathrm{H}$ chemical shift changes were observed upon addition of acetate anions to 1-4. Major deshielding of $\mathrm{H} 1$ protons in 1-4 is consistent with a strong interaction with acetate anions. ${ }_{60}$ Additionally, significant $\Delta \delta$ values of $\mathrm{H} 2 \beta$ and $\mathrm{H} 7 \alpha$ show acetate anions are strongly interact with the other two donor groups in $\mathbf{1}$ and $\mathbf{4}$. In conclusion, acetate and nitrate are both planar oxoanions that are predisposed for bidentate interactions with the urea and thiourea moieties in $\mathbf{2}$ and $\mathbf{3}$. ${ }_{65}$ Larger chemical shift changes in 1-4 upon addition of acetate with respect to nitrate anions are consistent with the lower basicity of nitrate.

Substituents attached to the indole $\mathrm{C} 2$ and $\mathrm{C} 7$ carbons make the resultant anion receptors conformationaly flexible. Four 70 conformers with respect to the orientations across $\mathrm{C} 2-\mathrm{C} 2 \alpha$ and $\mathrm{C} 7-\mathrm{N} 7 \alpha$ bonds are expected to be preferred (Figure 6). A preliminary $a b$ initio computational study of $\mathrm{C} 2$ and $\mathrm{C} 7$ functionalized indoles showed that the anti-anti conformer is energetically preferred in the absence of anions, whereas the 75 syn-syn conformer is favored for anion-receptor complexes.
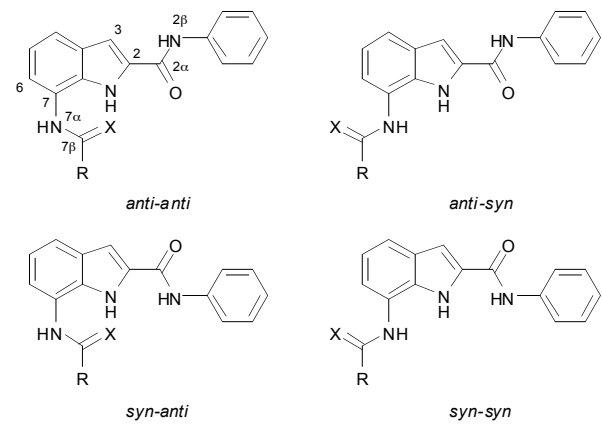

Figure 6. Four major conformational families with respect to $\mathrm{C} 2$ and $\mathrm{C} 7$ substituents in indole receptors. The first notation of individual conformer refers to the orientation along N1-C2-C2 $\alpha-\mathrm{N} 2 \beta$, while the second refers 80 to $\mathrm{C} 6-\mathrm{C} 7-\mathrm{N} 7 \alpha-\mathrm{C} 7 \beta$ fragment. R stands for phenyl, benzyl and phenylamine substituents, whereas $\mathrm{X}$ symbolizes $\mathrm{O}$ or $\mathrm{S}$ atom as shown in Figure 1.

Conformational preorganization of derivatives 1-4 has been assessed by NOE enhancements. 1D difference NOE ${ }_{85}$ experiments showed strong $\mathrm{H} 2 \beta-\mathrm{H} 3$ and negligible $\mathrm{H} 2 \beta-\mathrm{H} 1$ NOEs in the absence of anions which suggested the predominance of an anti orientation along $\mathrm{C} 2-\mathrm{C} 2 \alpha$ bonds in the receptors 1-4. A relatively strong NOE between $\mathrm{H} 7 \alpha-\mathrm{H} 6$ together with weak NOE between $\mathrm{H} 7 \alpha$ and $\mathrm{H} 1$ is evidence 90 that supports the predominance of an anti orientation along C $7-\mathrm{N} 7 \alpha$ bond in the absence of anions. The prevalent antianti conformers of 1-4 where the substituents' $\mathrm{NH}$ groups are pointing away from indole $\mathrm{H} 1$ proton are in agreement with negligible $\mathrm{H} 1-\mathrm{H} 2 \beta$ and $\mathrm{H} 1-\mathrm{H} 7 \alpha$ NOE enhancements. ${ }_{95}$ Arrangement of $\mathrm{C} 2 \alpha$ and $\mathrm{C} 7 \beta$ carbonyl groups in anti-anti orientation is predisposed to act as intramolecular hydrogen bond acceptors for the $\mathrm{H} 1$ proton.

The addition of anions to receptors 1-4 resulted in significant changes of key NOE enhancements. A major 100 decrease of $\mathrm{H} 2 \beta-\mathrm{H} 3$ as well as minor decrease of $\mathrm{H} 7 \alpha-\mathrm{H} 6$ NOEs occurred upon addition of chloride, bromide and acetate anions. Simultaneous increases of NOEs among H1 and $\mathrm{H} 2 \beta$ as well as $\mathrm{H} 1$ and $\mathrm{H} 7 \alpha$ furthermore suggested a conformational conversion of the receptors from anti-anti to 105 syn-syn upon interaction with anions. Rotations along $\mathrm{C} 2-\mathrm{C} 2 \alpha$ 
and $\mathrm{C} 7-\mathrm{C} 7 \alpha$ bonds are also supported by $\mathrm{H} 6$ chemical shift changes. As this proton is not directly involved in anionreceptor interactions its $\Delta \delta$ values are most likely result of variations of chemical environment upon conformational 5 changes. No conformational changes were observed upon addition of nitrate anions to $\mathbf{1 - 4}$ as evidenced by almost unchanged NOE enhancements.

Our NMR data demonstrate that binding of chloride anions occurs primarily at $\mathrm{H} 1$ and $\mathrm{H} 2 \beta$ or $\mathrm{H} 7 \alpha$ (Figure $7 \mathrm{a}$ ) Analogous 10 interactions were established for receptors 1-4 upon addition of bromide anions. Proton chemical shift changes upon addition of nitrate anions to $\mathbf{1}$ and $\mathbf{4}$ suggest very weak interactions. However, introduction of urea or thiourea groups significantly improves the binding properties of nitrate to 2 15 and 3. Negligible NOE changes in nitrate complexes with 1-4 together with corresponding $\Delta \delta$ values indicate that interaction of $\mathrm{NO}_{3}^{-}$anions occurs through the urea (2) or thiourea (3) group without rotation along $\mathrm{C} 7-\mathrm{C} 7 \alpha$ bond (Figure 7b). Figure 7c illustrates the proposed binding mode 20 of acetate to 2 . Large chemical shift changes hint at strong interactions with indole and urea $\mathrm{NH}$ groups whereas interactions with $\mathrm{H} 2 \beta$ proton are weaker. Rotation from antianti to syn-syn conformer is anticipated in the other three acetate-receptor complexes but could not be confirmed 25 experimentally. a)

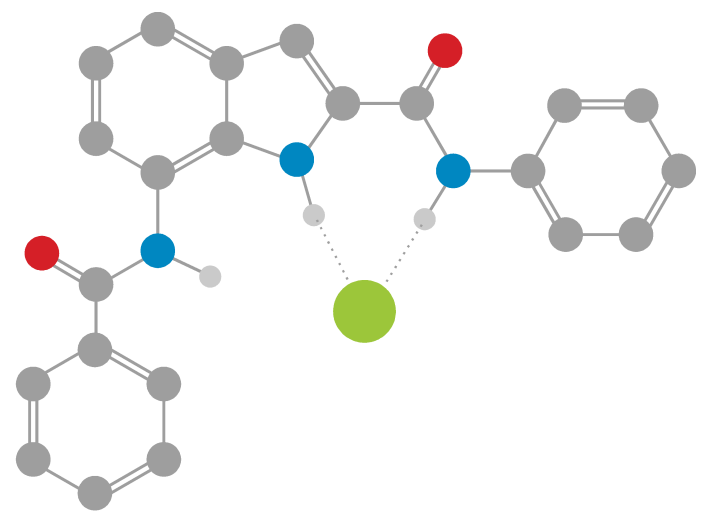

b)
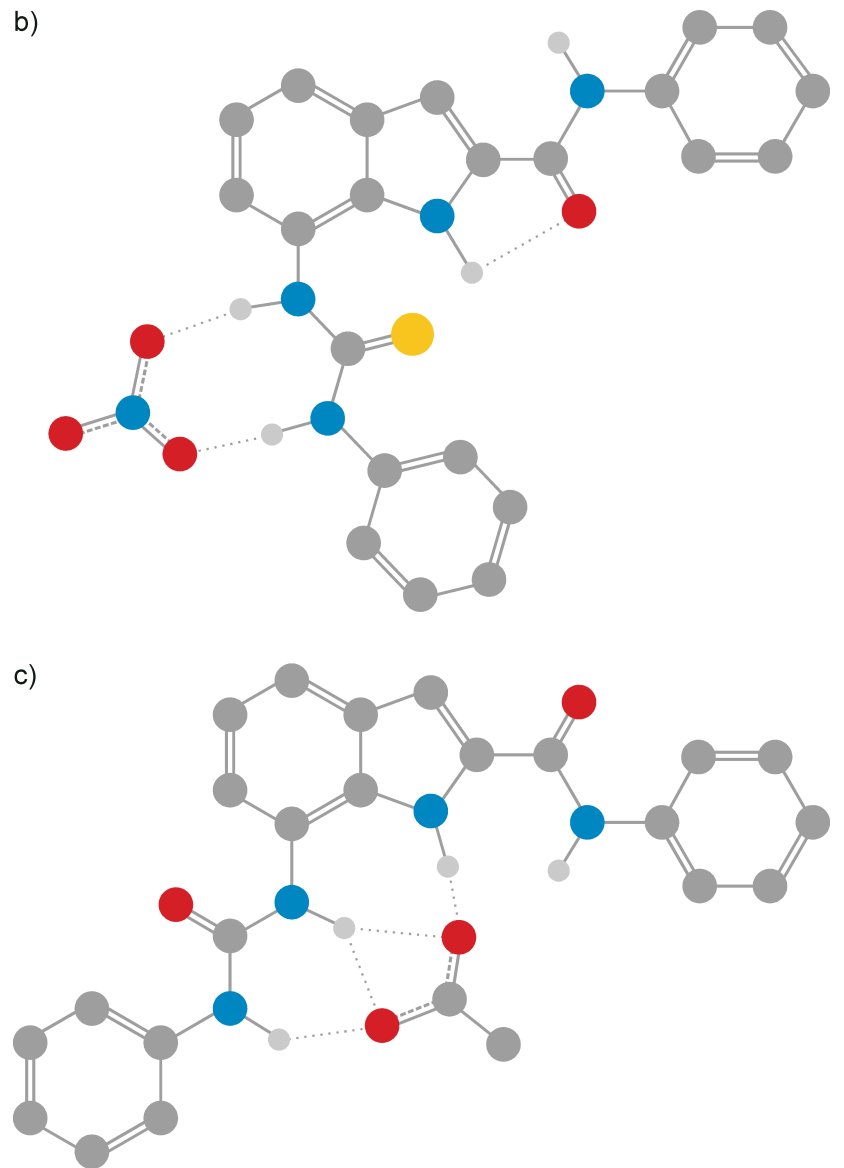

Figure 7. Conformations and positions of chloride anion in $4 \cdot \mathrm{Cl}^{-}$(a), nitrate anion in $\mathbf{3} \cdot \mathrm{NO}_{3}{ }^{-}$(b) and acetate anion in $\mathbf{2} \cdot \mathrm{AcO}^{-}$(c) complexes based on chemical shift changes and NOE enhancements.

\section{Conclusions}

Bis-amido and mono-amido-mono-urea 2,7-functionalised indoles 1-4 were characterized by heteronuclear NMR spectroscopy. The NOE based conformational analysis 35 revealed that all four receptors exhibit conformational preorganization in acetone solution, where anti-anti conformer is predominant. Such an orientation places $\mathrm{C} 2 \alpha$ and $\mathrm{C} 7 \beta$ carbonyl groups in the proximity of indole $\mathrm{H} 1$ proton which leads to stabilization by intramolecular hydrogen 40 bonds. Anion-induced chemical shift changes demonstrate that binding of halides (chloride, bromide) takes place predominantly at $\mathrm{H} 1$ proton. Receptors $\mathbf{2}$ and $\mathbf{3}$ with urea and 
thiourea moieties offer more donor groups and therefore the anions interact with $\mathrm{H} 1, \mathrm{H} 7 \alpha$ and $\mathrm{H} 7 \gamma$ protons. Nitrate anions favor interaction with $\mathrm{H} 7 \alpha$ and $\mathrm{H} 7 \gamma$ urea and thiourea protons, whereas acetate anions interact strongly with all available 5 hydrogen bond donors. Comparison of NOE enhancements in the absence and in the presence of anions revealed conformational changes of receptors 1-4 induced by complexation of chloride, bromide and acetate anions. Anionreceptor complexes preferably adopt syn-syn conformation

10 where all NH protons are spatially close and involved in interaction with anions. However, no conformational changes were observed upon addition of nitrate anions to 1-4. Our study demonstrates that indole ring offers intriguing scaffold for design of novel anion receptors and their modification in 15 order to tune affinities and selectivities for anions.

\section{Acknowledgments}

The authors gratefully acknowledge the Slovenian Research Agency (ARRS, Program No. P1-0242), the EPSRC and COST D31/0021/05 for financial support.

\section{${ }_{20}$ Notes and references}

a Slovenian NMR Center, National Institute of Chemistry, Hajdrihova 19, SI-1000 Ljubljana, Slovenia

${ }^{b}$ Faculty of Chemistry and Chemical Technology, University of

Ljubljana, SI-1000 Ljubljana, Slovenia

${ }_{25}{ }^{c}$ School of Chemistry, University of Southampton, Southampton SO17 1 BJ, United Kingdom

E-mails:philip.gale@soton.ac.uk; janez.plavec@ki.si; Gale:Tel +44 23 8059 3332; Fax +44 238059 6805; Plavec: Tel: +386 14760 353; Fax: +38614760300 .

30

1. A. Bianchi, K. Bowman-James and E. Garcia-España, Eds., Supramolecular Chemistry of Anions, Wiley-VCH, New York, 1997.

2. J. L. Sessler, P. A. Gale and W. S. Cho, Anion Receptor Chemistry, Royal Society of Chemistry, Cambridge, 2006.

35 3. P. D. Beer and P. A. Gale, Angew. Chem. Int. Ed., 2001, 40, 486516.

4. K. Bowman-James, Acc. Chem. Res., 2005, 38, 671-678.

5. R. Vilar, Eur. J. Inorg. Chem., 2008, 357-367.

6. P. A. Gale, S. E. Garcia-Garrido and J. Garric, Chem. Soc. Rev., 2008, 37, 151-190.

7. C. Caltagirone and P. A. Gale, Chem. Soc. Rev., 2009, 38, 520-563.

8. J. W. Pflugrath and F. A. Quiocho, J. Mol. Biol., 1988, 200, 163-180.

9. K. H. G. Verschueren, F. Seljee, H. J. Rozeboom, K. H. Kalk and B. W. Dijkstra, Nature, 1993, 363, 693-698.

45 10. P. A. Gale, Chem. Commun., 2008, 4525-4540.

11. C. Caltagirone, P. A. Gale, J. R. Hiscock, S. J. Brooks, M. B. Hursthouse and M. E. Light, Chem. Commun., 2008, 3007-3009.

12. C. Caltagirone, J. R. Hiscock, M. B. Hursthouse, M. E. Light and P. A. Gale, Chem. Eur. J., 2008, 14, 10236-10243.

50 13. J.-m. Suk, M. K. Chae, N.-K. Kim, U.-1. Kim and K.-S. Jeong, Pre Appl. Chem., 2008, 80, 599-608.

14. G. W. Bates, P. A. Gale and M. E. Light, Chem. Commun., 2007, 2121-2123.

15. F. M. Pfeffer, K. F. Lim and K. J. Sedgwick, Org. Biomol. Chem., 2007, 5, 1795-1799.

16. J. L. Sessler, D. G. Cho and V. Lynch, J. Am. Chem. Soc., 2006, 128, 16518-16519.

17. K.-J. Chang, M. K. Chae, C. Lee, J.-Y. Lee and K.-S. Jeong, Tetrahedron Lett., 2006, 47, 6385-6388.

60 18. K.-J. Chang, D. Moon, M. S. Lah and K.-S. Jeong, Angew. Chem. Int. Ed., 2005, 44, 7926-7929.
19. K. J. Chang, B. N. Kang, M. H. Lee and K. S. Jeong, J. Am. Chem. Soc., 2005, 127, 12214-12215.

20. S. O. Kang, R. A. Begum and K. Bowman-James, Angew. Chem. Int. Ed., 2006, 45, 7882-7894.

21. J. L. Sessler, S. Camiolo and P. A. Gale, Coord. Chem. Rev., 2003, 240, 17-55.

22. C. R. Bondy and S. J. Loeb, Coord. Chem. Rev., 2003, 240, 77-99.

23. D. A. Jose, A. Singh, A. Das and B. Ganguly, Tetrahedron Letters, 2007, 48, 3695-3698.

24. D. E. Gomez, L. Fabbrizzi, M. Licchelli and E. Monzani, Organic \& Biomolecular Chemistry, 2005, 3, 1495-1500.

25. G. W. Bates, Triyanti, M. E. Light, M. Albrecht and P. A. Gale, J. Org. Chem., 2007, 72, 8921-8927. 